\title{
Transient Characteristics of Two Wind Turbine Generator Systems Having Two Types of Control Methods*
}

\author{
Sumio SAITO ${ }^{* *, * * *}$ Satoshi SEKIZUKA ${ }^{* * * *}$ and Kenichi SATO ${ }^{* * * *}$ \\ **Now: Department of Mechanical Engineering, Tokyo National College of Technology, \\ 1220-2 Kunugida-machi, Hachioji-shi, Tokyo, 193-0997, Japan \\ E-mail: saito@tokyo-ct.ac.jp \\ ${ }^{* * *}$ Formerly: Ebara Corporation, \\ 11-1 Haneda Asahi-cho, Ohta-ku, Tokyo 144-8510, Japan \\ ****Wind Energy Division, New and Renewable Energy Company, EBARA Corporation, \\ 11-1 Haneda Asahi-cho, Ohta-ku, Tokyo 144-8510, Japan \\ E-mail: sekizuka.satoshi@ebara.com
}

\begin{abstract}
Wind turbines operate in strong wind conditions, which are generally irregular and unsteady. The previous paper reports a study on two wind turbine generator systems having different types of control methods at a site. It discusses the characteristics of these wind turbines with respect to their control methods by clarifying the relationship between wind parameters and various electric parameters under steady wind conditions. Wind behavior can change drastically, particularly in the transition of output power, for instance when a wind turbine starts up or stops. Therefore, understanding the transient behavior of various electric parameters is beneficial in comprehensively evaluating the performance of a wind turbine generator system. This paper further reports on the same two wind turbine generator systems. Their electric parameters when the output power of the turbines is changed are measured and their performances during their transient state are also discussed.
\end{abstract}

Key words: Wind Turbine, Wind Turbine Generator System, Propeller Type Wind Turbine, Power Control, Constant Speed Wind Turbine, Variable Speed Wind Turbine, Wind Speed, Induction Generator, Asynchronous Generator, Power Curve

\section{Introduction}

A great number of horizontal axis propeller type wind turbines are in service around the world. As the generator for their wind power generator system, the turbines employ either a synchronous generator or an asynchronous generator, represented respectively by the wound-rotor induction generator and the squirrel-cage induction generator. The applied generator type determines the output power of the turbines and the control method of the generator speed $^{(1)(2)(3)}$.

Wind turbines are often used in strong wind conditions that are non-uniform and highly unsteady. For their operation, particularly in mountainous areas such as Japan, it is important to evaluate how the applied control method affects parameters of the wind power generator system at various wind speeds.

Our previous report ${ }^{(4)}$ compared two types of on-site wind power generator systems

*Received 27 Nov., 2006 (No. T-04-0362) Japanese Original : Trans. Jpn. Soc. Mech. Eng., Vol.71, No.702, B (2005), pp.539-545 (Received 31 Mar., 2004) [DOI: 10.1299/jee.2.13] 
with different control methods with regard to such technical details. It also clarified the relationship between the wind conditions and electrical parameters when the systems are in steady state, and discussed the characteristics of their performances with each control method.

Wind conditions are ever-changing, even when a wind turbine is in steady state. In particular, when the output power of a wind turbine suddenly changes, for instance when it starts up or stops, the wind turbine is effected more drastically by changes in wind conditions than when the wind turbine is in steady state. Therefore, it is important to understand the transient behavior of various electric parameters for the evaluation of the overall performance of a wind turbine generator system.

This report, using the two turbines with different control methods studied in our previous report $^{(4)}$, discusses electrical parameters, which were measured when the output power changed, including its startup, and the turbine performances during the transient change.

\section{Symbols}

$D$ : Rotor diameter

$E$ : Voltage

$f$ : IGBT (Insulated Gate Bipolar Transistor) frequency

$H$ : Hub height (plumb line distance from the ground surface to the rotor center)

$I$ : Current

$N$ : Generator speed

$P$ : Active power, Output power

$V_{l}$ : Wind speed on the meteorological mast

$V_{2}$ : Wind speed on the nacelle (wind speed measured by a newly installed anemometer) $\mathrm{m}$

$\mathrm{V}$

$\mathrm{Hz}$

$\mathrm{m}$

A rpm $\left(\right.$ or $\min ^{-1}$ )

$\mathrm{kW}$

$\mathrm{m} / \mathrm{s}$

$\mathrm{m} / \mathrm{s}$

\section{Specifications of the studied wind turbines}

Table 1 shows the specifications of the studied wind turbines. Though these wind turbines are installed at different sites, both sites are located in Hokkaido and connected to high-voltage distribution lines.

Table 1 Specifications of studied wind turbines

\begin{tabular}{|c|c|c|c|c|}
\hline \multicolumn{2}{|c|}{ Specification } & Wind turbine A & Wind turbine B \\
\hline \multirow{2}{*}{ Power control } & Blade & - & Variable pitch type & Stall type \\
\cline { 2 - 5 } & Generator & - & $\begin{array}{c}\text { Wound-rotor } \\
\text { induction generator }\end{array}$ & $\begin{array}{c}\text { Squirrel-cage } \\
\text { induction generator }\end{array}$ \\
\hline Nominal rated power & $P_{0}$ & $450 \mathrm{~kW}$ & $750 / 200 \mathrm{~kW}$ \\
\hline Rated wind speed & $V n$ & $11.5 \mathrm{~m} / \mathrm{s}$ & $16 \mathrm{~m} / \mathrm{s}$ \\
\hline Cut-in wind speed & $V i$ & $2.5 \mathrm{~m} / \mathrm{s}$ & $4 \mathrm{~m} / \mathrm{s}$ \\
\hline Cut-out wind speed & $V o$ & $25 \mathrm{~m} / \mathrm{s}$ & $25 \mathrm{~m} / \mathrm{s}$ \\
\hline Rotor diameter & $D$ & $45.8 \mathrm{~m}$ & $48.2 \mathrm{~m}$ \\
\hline Hub height & $H$ & $50 \mathrm{~m}$ & $45 \mathrm{~m}$ \\
\hline Rotor speed & $n$ & $14 \sim 29 \mathrm{rpm}$ & $22 / 15 \mathrm{rpm}$ \\
\hline
\end{tabular}


Wind turbine A has a nominal rated power of $450 \mathrm{~kW}$ and a cut-in wind speed of 2.5 $\mathrm{m} / \mathrm{s}$. It has three variable-pitch blades, which change the pitch angle to control the output power. The turbine is equipped with an asynchronous wound-rotor induction generator, which can control variable speed operation.

Wind turbine $B$ has a nominal rated power of $750 \mathrm{~kW}$ and a cut-in wind speed of $4 \mathrm{~m} / \mathrm{s}$. It has three blades, which employ a blade tip mechanism for stall control. The turbine is equipped with an asynchronous squirrel-cage induction generator, which performs pole change to change the generator speed at two stages.

\section{Measurement method}

Figure 1 shows the measurement items and measuring steps. The same measurement method as the previous report ${ }^{(4)}$ was applied.

An additional propeller type anemometer mounted on the top of the nacelle, which houses major components, such as the generator and gearbox and is located at the top of the tower, was used to measure the wind speed. An anemometer mounted on a $50 \mathrm{~m}$ high meteorological mast was also used. To compare and discuss the electrical influence of the transient behavior, along with the output power change, over the two wind turbine systems, all parameters, including the generator speed, active power, voltage, and current, were sampled in 0.1-second intervals and recorded in a data recorder (digital oscilloscope). For wind turbine $\mathrm{A}$, the rotor speed was detected and the difference between the power frequency and the actual frequency was adjusted to control variable speed operation. Since this adjustment was electrically performed by a frequency control unit using an insulated gate bipolar transistor (hereinafter called, $\operatorname{IGBT}^{(4)}$ ), the IGBT frequency was also measured during output power generation.



Fig. 1 Measurement system

\section{Results and discussion}

\subsection{Performance of wind turbine $A$ in steady state and in transient state}

\subsubsection{Power curve in steady state}

Figure 2 shows the performance of wind turbine A with regard to the relationship between the wind speed on the meteorological mast and the output power, as 1-minute average data. The measurements of output power in comparison to the nominal rated 
power are shown in the figure in the same manner as in the previous report ${ }^{(4)}$ and they are divided into the following three operating regions.

Region [1]: Region in which the wind speed was under the cut-in wind speed.

Region [2]: Region in which the wind speed ranged from the cut-in wind speed to the level of the generator speed reaching the synchronous speed $(N=1000 \mathrm{rpm})$.

Region [3]: Region in which the generator speed ranged from the synchronous speed $(N=1000 \mathrm{rpm})$ to the nominal rated power.

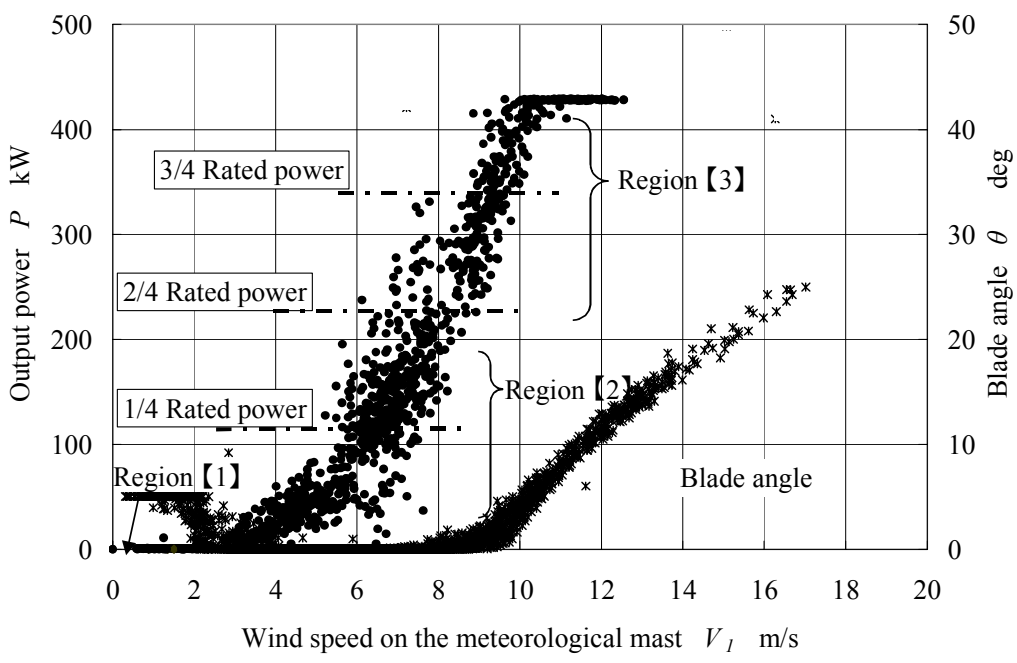

Fig. 2 Power curve

\subsubsection{Performance in transient state}

(a) Transient performance of the wind turbine when the output power rose from $0 \mathrm{~kW}$ (when the output power transited from Region [1] to Region [2]).

Figure 3 shows 0.1 -second data indicating the transient change in various electrical parameters, including the active power and current, and the wind speed on the meteorological mast and the nacelle, as well as the change in the generator speed when the output rose from $0 \mathrm{~kW}$.

Until the wind speed reached the cut-in wind speed (Region [1]), the wind speed on the nacelle remained at $3 \mathrm{~m} / \mathrm{s}$ or less on average, which was the level when the generator speed fluctuated from 700 to $900 \mathrm{rpm}$. Though it is not indicated in the figure, no active power was generated before the wind speed reached the cut-in speed, as in the case when the generator speed rose from the stop state.

At the cut-in speed, the active power and current showed sudden increases to approximately $120 \mathrm{~kW}$ and 90 A respectively, whereas the voltage showed almost no change. At this point, the IGBT frequency indicated an instantaneous rise and the generator speed suddenly changed from $900 \mathrm{rpm}$ to $700 \mathrm{rpm}$.

After reaching the cut-in speed, the wind speed increased to approximately $8 \mathrm{~m} / \mathrm{s}$ as time elapsed and the active power gradually increased to approximately $150 \mathrm{~kW}$ (about $30 \%$ of the nominal rated power) in the final stage shown in Fig.3 (Region [2]).

In the process of the change, the waveforms, which show the change in the active power and current over time, indicate a close similarity and have a direct connection with the change in the wind speed on the meteorological mast and the nacelle over time.

After reaching the cut-in speed, the IGBT frequency increased to $15 \mathrm{~Hz}$ when the generator speed was $700 \mathrm{rpm}$. At this level, the deficit in frequency, which is equivalent to the difference of the frequency between $1000 \mathrm{rpm}$ (synchronous speed, shown with a dashed line in Fig. 3) and 700 rpm, was supplied from the grid-connected to the generator 
rotor. When the wind speed increased, the change in the IGBT frequency showed the reverse response to the up/down of the generator speed ${ }^{(4)}$.
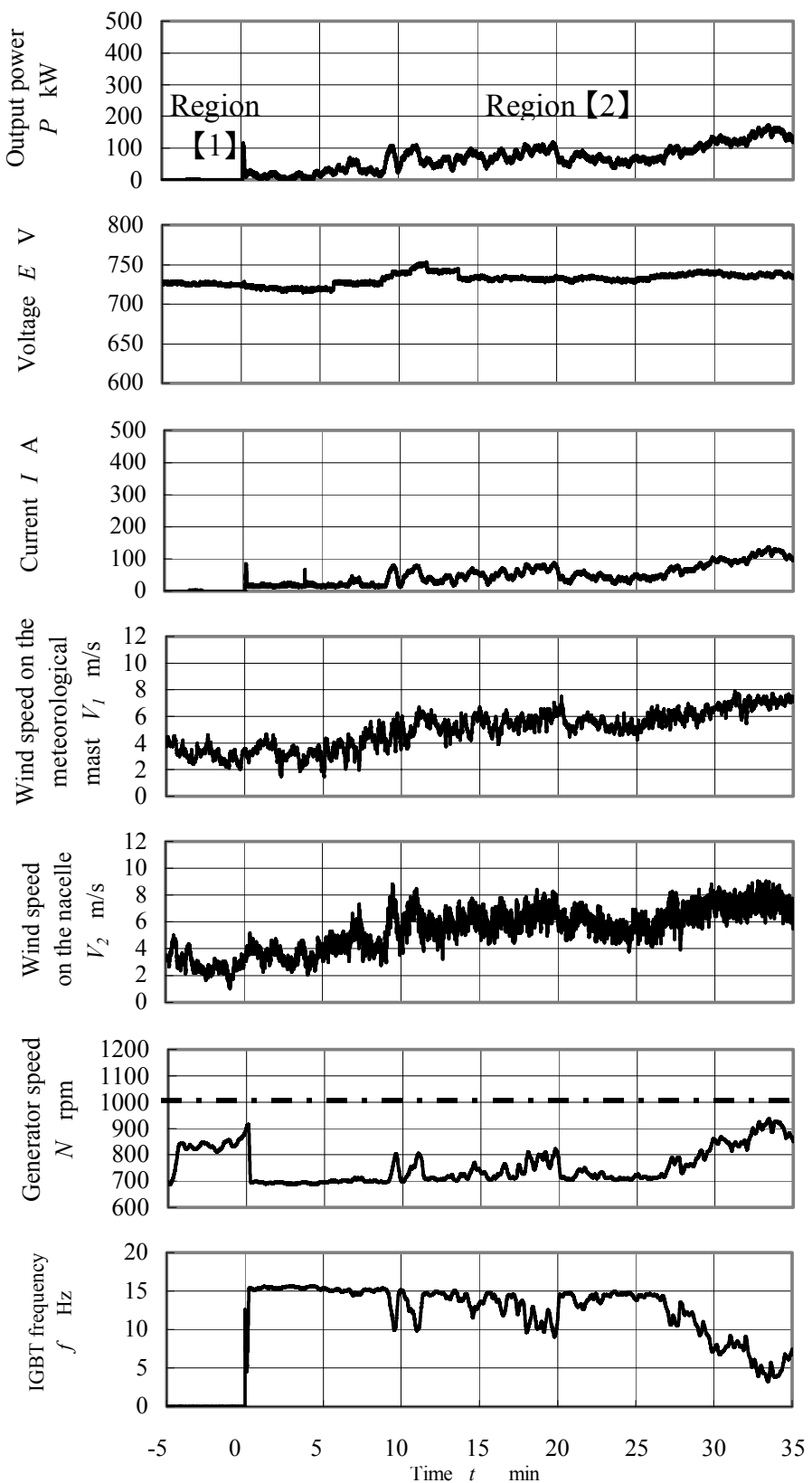

Fig. 3 Waveforms of parameters in output power starting from $P=0 \mathrm{~kW}$

(b) Transient performance of the wind turbine when the output power transited from Region [2] to Region [3]

Figure 4 shows the transient change in various electrical parameters, including the active power and current, and the wind speed on the meteorological mast and the nacelle, as well as the change in the generator speed and IGBT frequency over time when the output power suddenly increased by approximately $200 \mathrm{~kW}$ to reach Region [3], from approximately $100 \mathrm{~kW}$ (Region [2]).

In the process of the change, the active power transiently increased from approximately $100 \mathrm{~kW}$ to $360 \mathrm{~kW}$ and the waveform indicating the change in the current over time increased from approximately $80 \mathrm{~A}$ to values over $300 \mathrm{~A}$, which, however, was not the instantaneous change as observed in wind turbine B (described later). 

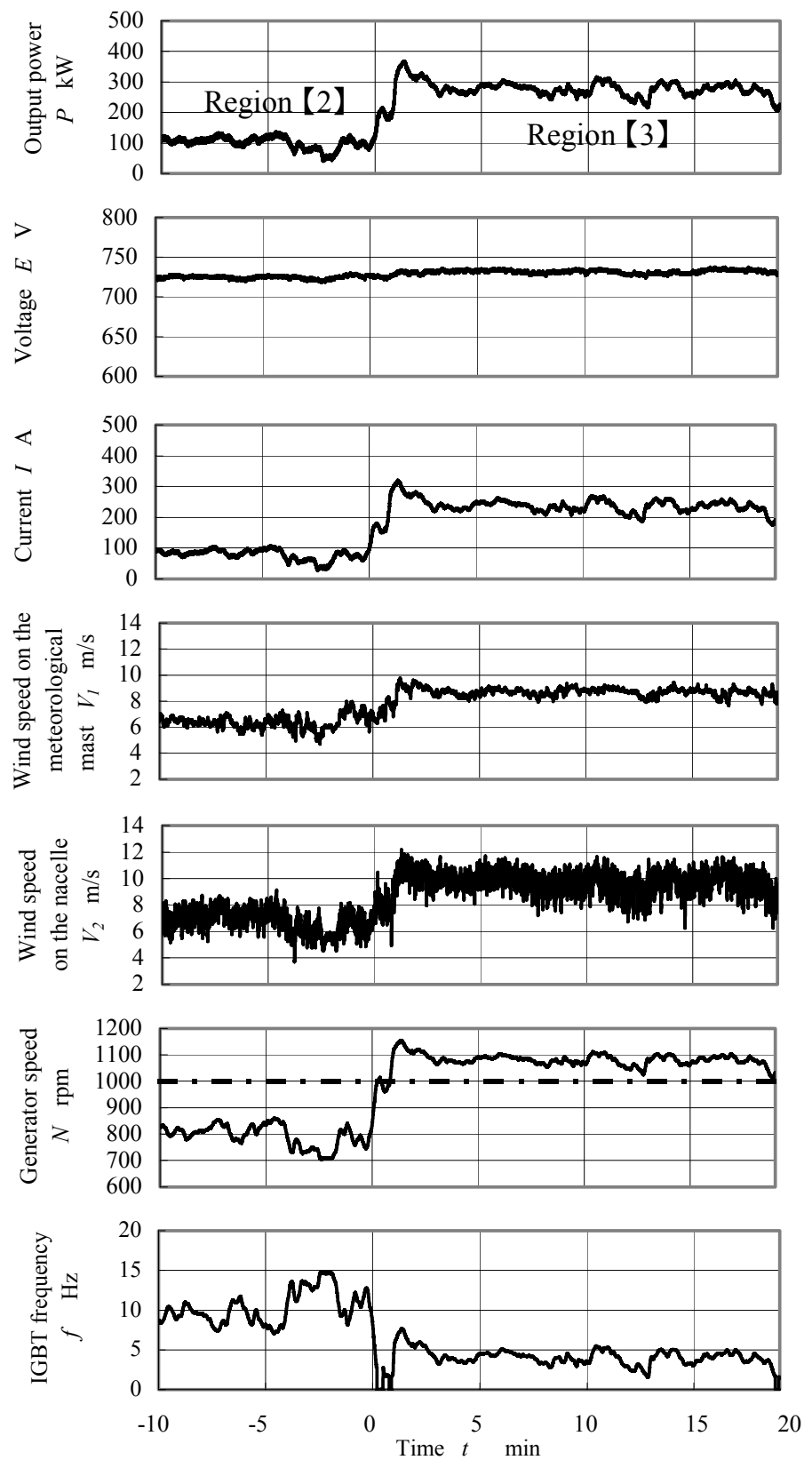

Fig. 4 Waveforms of parameters in sudden change of output power

Furthermore, the waveform of the voltage shows almost no change from approximately $725 \mathrm{~V}$. As in the case of the transient change when the output rose from $0 \mathrm{~kW}$, as described above, the waveforms, which show the change in the active power and the current over time, indicate a close similarity and have a direct connection primarily with the change in the wind speed over time.

The IGBT frequency shows the waveform, which is the reverse of that of the generator speed, when the generator speed was $800 \mathrm{rpm}$ (Region [2]). At this level, approximately $10 \mathrm{~Hz}$, which is equivalent to the difference of the frequency between $1000 \mathrm{rpm}$ (synchronous speed, shown with a dashed line in Fig. 4) and $800 \mathrm{rpm}$, was supplied from the grid-connected to the generator rotor.

In Region [3], on the other hand, where the generator speed exceeded the synchronous speed of $1000 \mathrm{rpm}$, the generator speed reached approximately $1100 \mathrm{rpm}$ and a comparatively excessive frequency of approximately $5 \mathrm{~Hz}$ was supplied to the 
grid-connected through the IGBT in order to retain a power frequency of $50 \mathrm{~Hz}$. At this point, the change in the IGBT frequency corresponded to the change in the generator speed $^{(4)}$ over time.

Although it is not shown in the figure, when the wind speed decreased from a level outputting the nominal rated power to approximately $100 \mathrm{~kW}$, the change in various electrical parameters, including the active power and current, the wind speed on the meteorological mast and the nacelle, and the change in the generator speed and the IGBT frequency over time, basically indicated a change similar to the sudden change in output power in the aforementioned case, except for the fact that the output power decreased.

(c) Loci of the transient change

While the power curve of the wind turbine shown in Fig. 2 contains variation, Fig. 5 indicates with diagrams the average power curve in relation to the generator speed and the IGBT frequency.

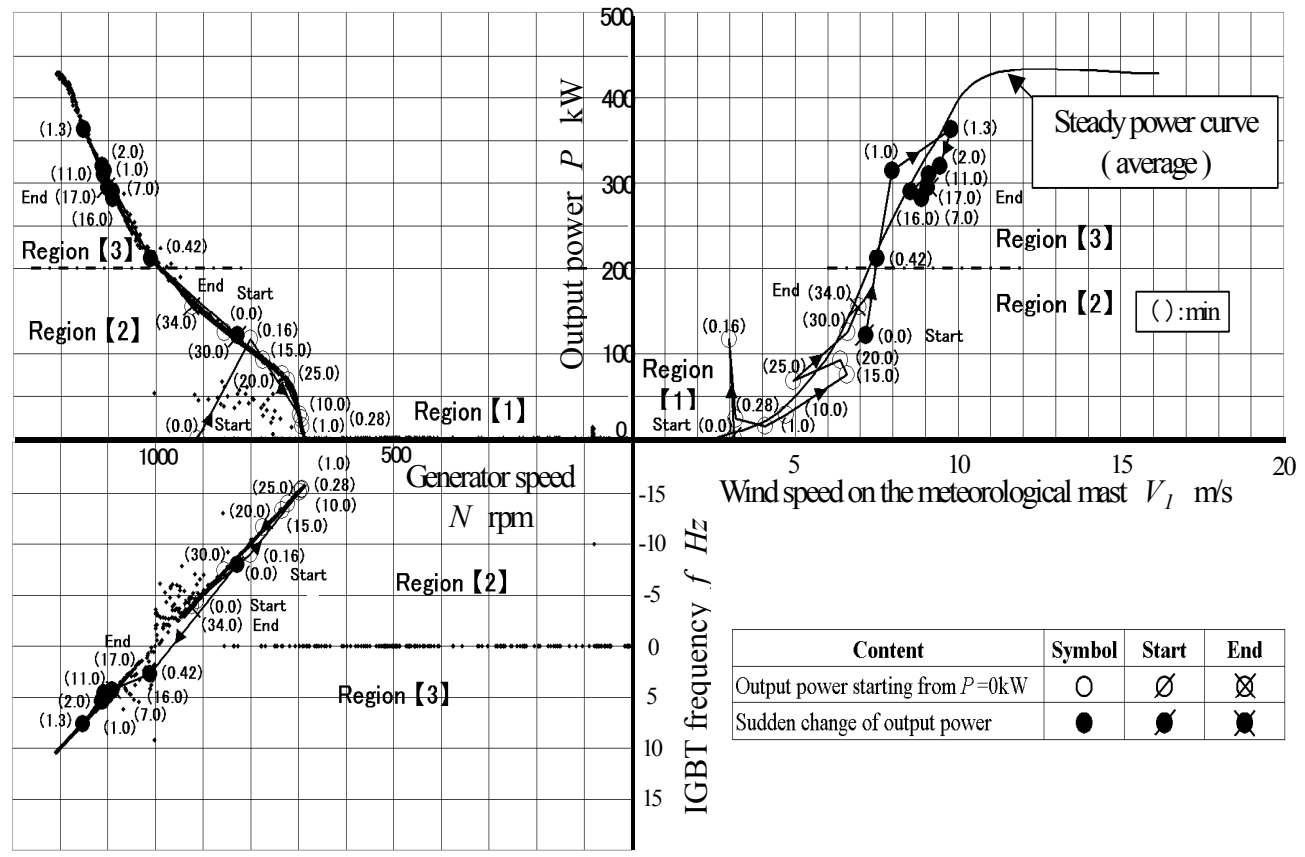

Fig. 5 Loci of operating points in output power transition (Wind turbine A)

In these diagrams, the loci of the transient change in various electrical parameters, with the output power starting from $P=0 \mathrm{~kW}$ (in transition from Region [1] to Region [2]) in the aforementioned case, and in this case, with the output power suddenly increasing by approximately $200 \mathrm{~kW}$ from $100 \mathrm{~kW}$ (in transition from Region [2] to Region [3]), are also described.

The starting point of the loci was set to the state just before the output power changed from $0 \mathrm{~kW}$, specifically, when the generator speed reached approximately $900 \mathrm{rpm}$. The change in the active power, generator speed, and IGBT frequency over time, after the starting point, is indicated by white circles. The values in parenthesis indicate the elapsed time, in minutes, after the output power began changing from $0 \mathrm{~kW}$. In the same manner, the loci of the transient change in physical values when the output power suddenly changed from approximately $100 \mathrm{~kW}$ are indicated in black circles.

The locus of the active power versus the wind speed on the meteorological mast is slightly off the steady power curve just after the starting point, but almost follows the steady power curve with slight deviation as time elapses.

On the other hand, the curves showing the relationship between the generator speed and the active power and the relationship between the generator speed and the IGBT frequency draw the loci on the steady curves at every physical value during the transient change. In 
Region [2], the IGBT frequency is indicated in negative values as the deficit is supplied to the generator rotor. In Region [3], the IGBT frequency is indicated in positive values as the surplus is supplied to the grid-connected.

As described above, it is conceivable that the change in physical values, including the active power, generator speed, and IGBT frequency, in relation to the change in the wind speed, can be regarded as a quasi-steady change because they are controlled by detecting fluctuations over a certain period and averaging such fluctuations.

\subsection{Performance of wind turbine $B$ in steady state and in transient state}

\subsubsection{Power curve in steady state}

Figure 6 shows the performance of wind turbine B in steady state, as 1-minute average data, from the relationship between the wind speed on the meteorological mast and the active power. The measurements of output power against the nominal rated power are shown in the figure in the same manner as the previous report ${ }^{(4)}$.

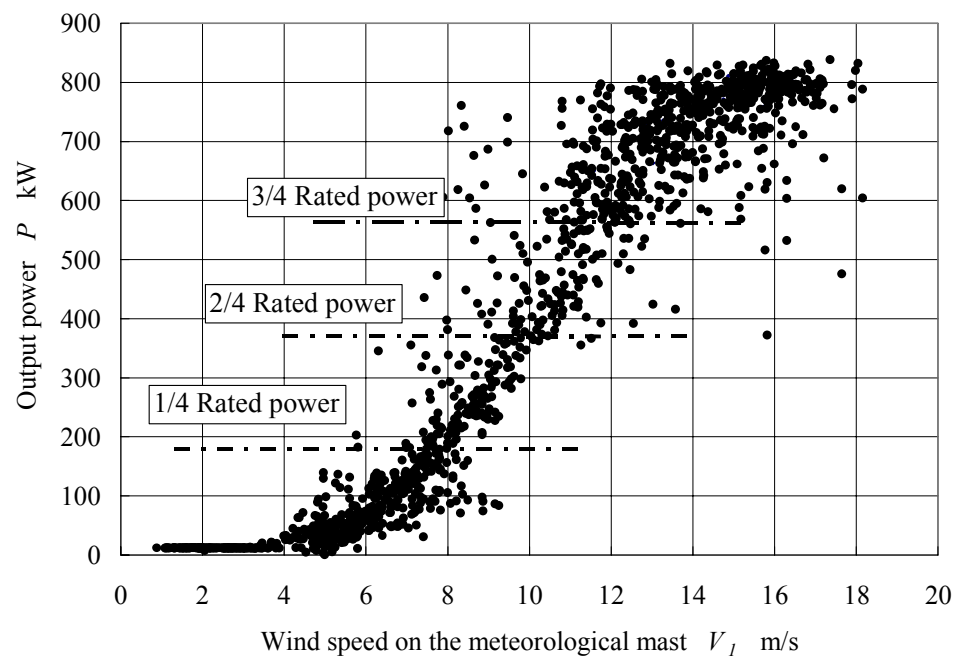

Fig. 6 Power curve

\subsubsection{Performance in transient state}

(a) Transient performance of the wind turbine when the generator speed changed from the stop state $(N=0 \mathrm{rpm})$ to the $\mathrm{P} 4$ state $(N=1500 \mathrm{rpm})$ via the $\mathrm{P} 6$ state $(N=1000 \mathrm{rpm})$

Figure 7 shows the transient change in various electrical parameters and the wind speed on the meteorological mast and the nacelle, as well as the change in the generator speed, when the generator speed increased from the stop state $(N=0 \mathrm{rpm})$ rising past $1000 \mathrm{rpm}$ (hereinafter called P6 state) to $1500 \mathrm{rpm}$ (hereinafter called P4 state).

The waveforms, which show the change in the wind speed on the meteorological mast and the nacelle over time, as well as the change in the wind speed values, indicate a close similarity. The wind conditions before starting generation of the active power were 5 to 10 $\mathrm{m} / \mathrm{s}$ in the wind speed values.

Studying the waveform of the wind speed more elaborately reveals that the generator speed instantly rose to $250 \mathrm{rpm}$ when the wind speed exceeded $5 \mathrm{~m} / \mathrm{s}$ and nearly reached 10 $\mathrm{m} / \mathrm{s}$. Then, it dropped once, though, after about 2 minutes, the generator speed quickly rose again to $1000 \mathrm{rpm}$ (the P6 state). 

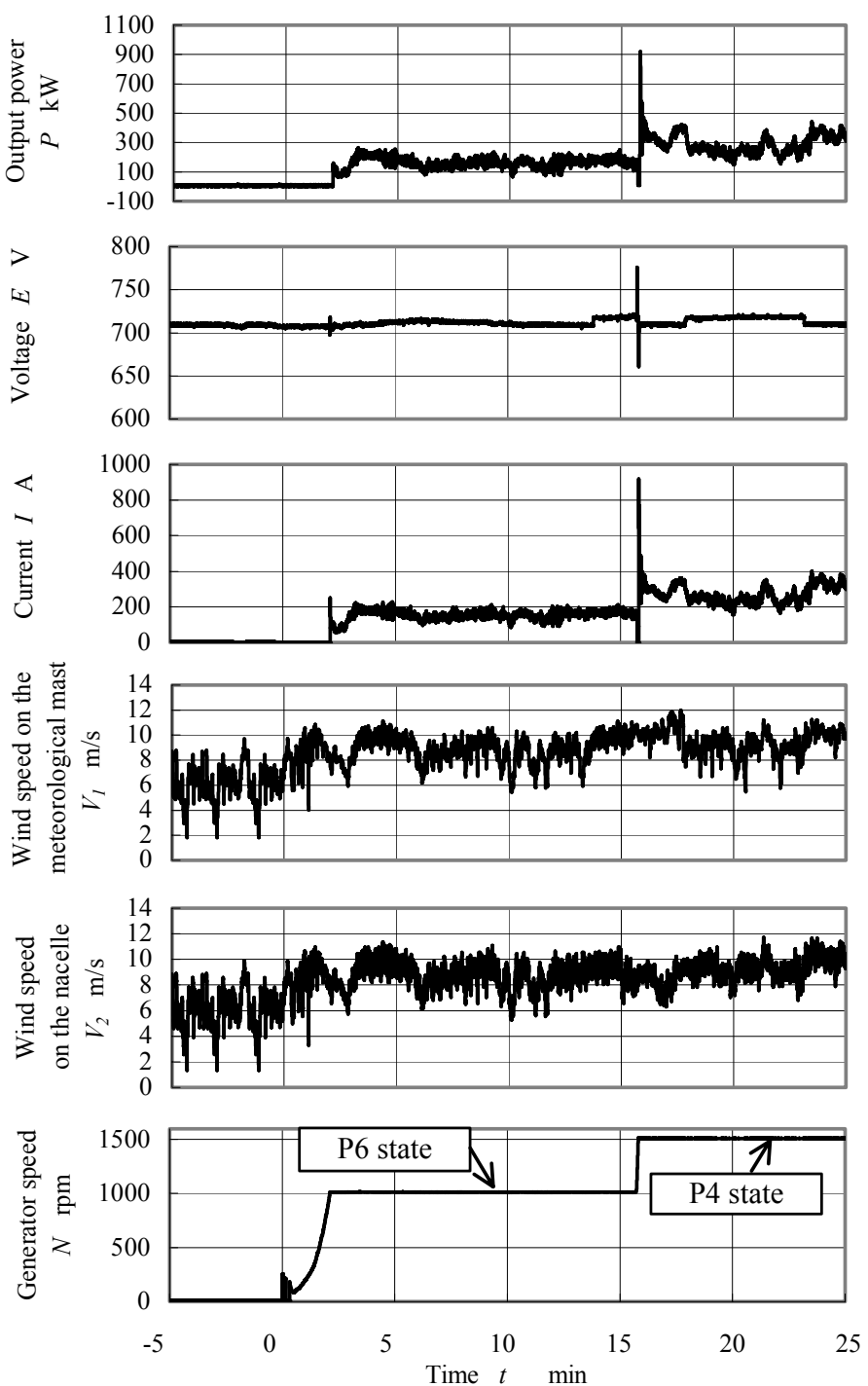

Fig. 7 Waveforms of parameters in generator run-up to P4 state via P6 state

At the moment the generator speed reached the P6 state $(N=1000 \mathrm{rpm})$, the active power instantly rose to approximately $150 \mathrm{~kW}$ (about $20 \%$ of the nominal rated power of $750 \mathrm{~kW}$ ) and the current rose to approximately $250 \mathrm{~A}$ (about $36 \%$ of the rated current of 700 A). At this moment, the waveform of the voltage also indicated an instantaneous change of $\pm 10 \mathrm{~V}$ from $715 \mathrm{~V}$. The fluctuations of the electrical parameters of wind turbine B were greater than those of wind turbine A. The waveforms, which show the change in the active power and current over time, indicate a similarity and reveal a close correlation between them.

In the region, where the wind speed ranged between approximately 7 and $10 \mathrm{~m} / \mathrm{s}$ or slightly exceeded these values, the generator maintained the P6 state and the generator speed stayed at $1000 \mathrm{rpm}$ steadily.

As the above wind speed values were maintained, the generator speed changed from the P6 state (1000 rpm) to the P4 state (1500 rpm). The P4 state was maintained as long as the wind speed ranged approximately $\pm 2 \mathrm{~m} / \mathrm{s}$ from $10 \mathrm{~m} / \mathrm{s}$.

When the generator speed transited from the P6 to P4 state, the active power instantly rose to $900 \mathrm{~kW}$ and the current indicated an inrush current of $920 \mathrm{~A}$ (about 1.3 times larger than the rated current). The waveform of the voltage showed a change of $\pm 60 \mathrm{~V}$ from 715 
V. This was an extremely large instantaneous change compared to the behavior of wind turbine A when it transited from Region [2] to Region [3].

While the P4 state was maintained, the waveforms, which show the temporal change in the active power and current, indicate a close similarity and have a direct connection with the temporal change in the wind speed on the meteorological mast and the nacelle, as in the case of wind turbine $\mathrm{A}$.

(b) Transient performance of the wind turbine when the generator speed transited from the $\mathrm{P} 4$ state $(N=1500 \mathrm{rpm})$ to the $\mathrm{P} 6$ state $(N=1000 \mathrm{rpm})$

Figure 8 shows transient performance when the generator speed changed from the $\mathrm{P} 4$ state $(N=1500 \mathrm{rpm})$ to the $\mathrm{P} 6$ state $(N=1000 \mathrm{rpm})$.
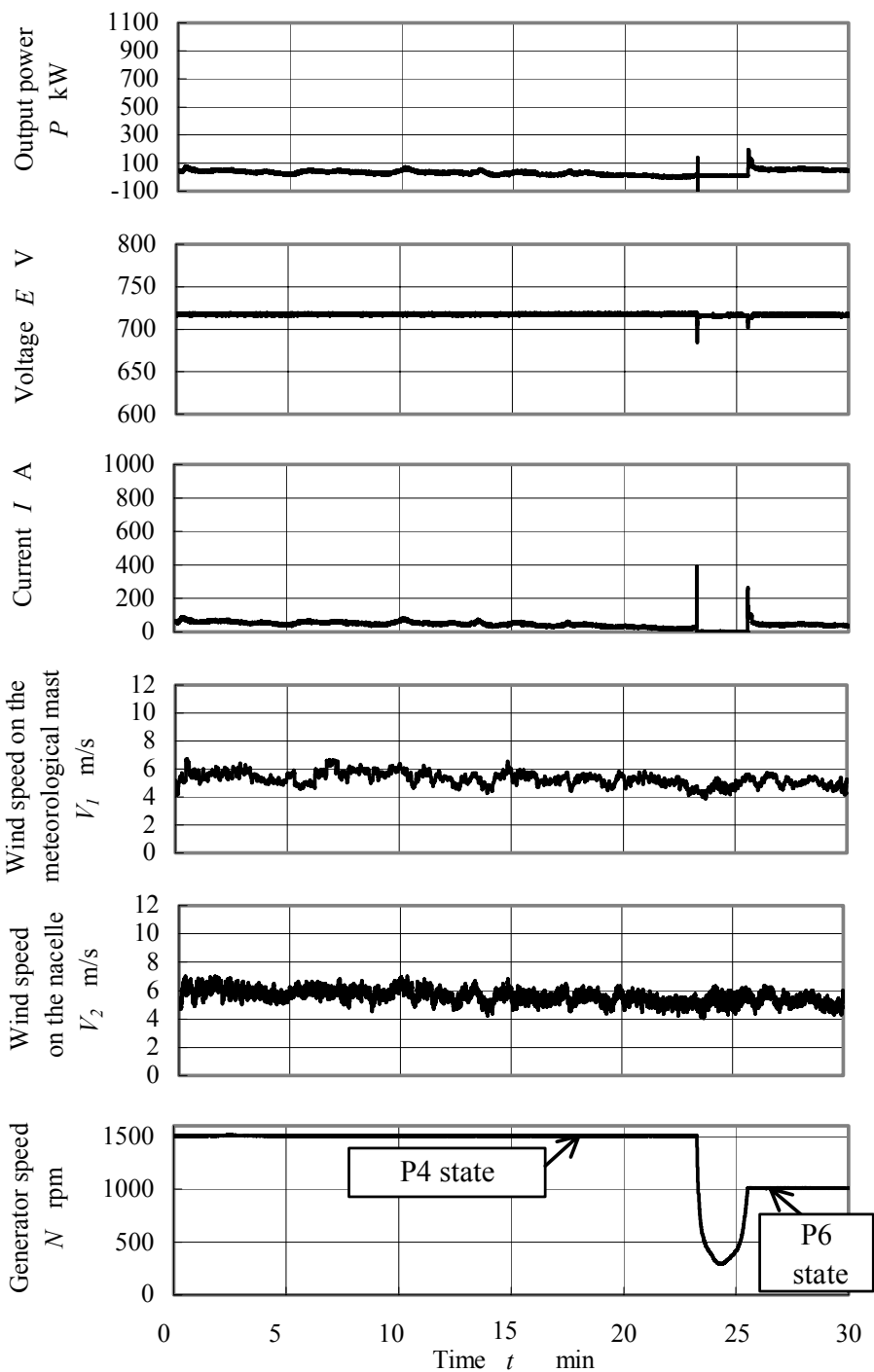

Fig. 8 Waveforms of parameters from P4 state $(N=1500 \mathrm{rpm})$ to $\mathrm{P} 6$ state $(N=1000 \mathrm{rpm})$

When the generator maintained the $\mathrm{P} 4$ state $(N=1500 \mathrm{rpm})$, the wind state indicated a wind speed of over $5 \mathrm{~m} / \mathrm{s}$. However, as the wind speed decreased, the active power and current also decreased gradually. When the wind speed fell to approximately $5 \mathrm{~m} / \mathrm{s}$, the generator was disconnected from the grid in the P4 state $(N=1500 \mathrm{rpm})$ and then transited to the P6 state $(N=1000 \mathrm{rpm})$. At this moment, the generator speed immediately dropped to $300 \mathrm{rpm}$ to prevent large electrical fluctuations during reconnection to the grid for 
transiting to the P6 state, and then increased again to reach the P6 state $(N=1000 \mathrm{rpm})$.

The active power instantly alternated above and below 0 , when the generator was disconnected from the grid in the $\mathrm{P} 4$ state $(N=1500 \mathrm{rpm})$. Furthermore, the active power sharply rose to $200 \mathrm{~kW}$, when the generator was reconnected to the grid in the P6 state and then remained steady at approximately $50 \mathrm{~kW}$ and maintained the P6 state.

As for the current, the inrush current of approximately 400 A was instantly generated when the generator was disconnected from the grid in the P4 state and an instantaneous current of approximately 270 A was generated when reconnected to the grid in the P6 state.

As for the voltage, instantaneous drops of approximately $35 \mathrm{~V}$ and $10 \mathrm{~V}$ respectively from a steady voltage of approximately $715 \mathrm{~V}$ were recorded, when the generator was disconnected from the grid in the P4 state and reconnected to the grid in the P6 state.

(c) Loci of the transient change

While the power curve of the wind turbine shown in Fig. 6 contains variation, Fig. 9 indicates the average power curve in relation to the generator speed in the diagrams. In these diagrams, the loci of the transient change, when the generator speed transited from the stop state $(N=0 \mathrm{rpm})$ to the $\mathrm{P} 4$ state $(N=1500 \mathrm{rpm})$ via the $\mathrm{P} 6$ state $(N=1000 \mathrm{rpm})$, are indicated by white circles. In the same manner, the loci of the transient change, when the generator speed transited from the $\mathrm{P} 4$ state $(N=1500 \mathrm{rpm})$ to the $\mathrm{P} 6$ state $(N=1000 \mathrm{rpm})$, are indicated in black circles.

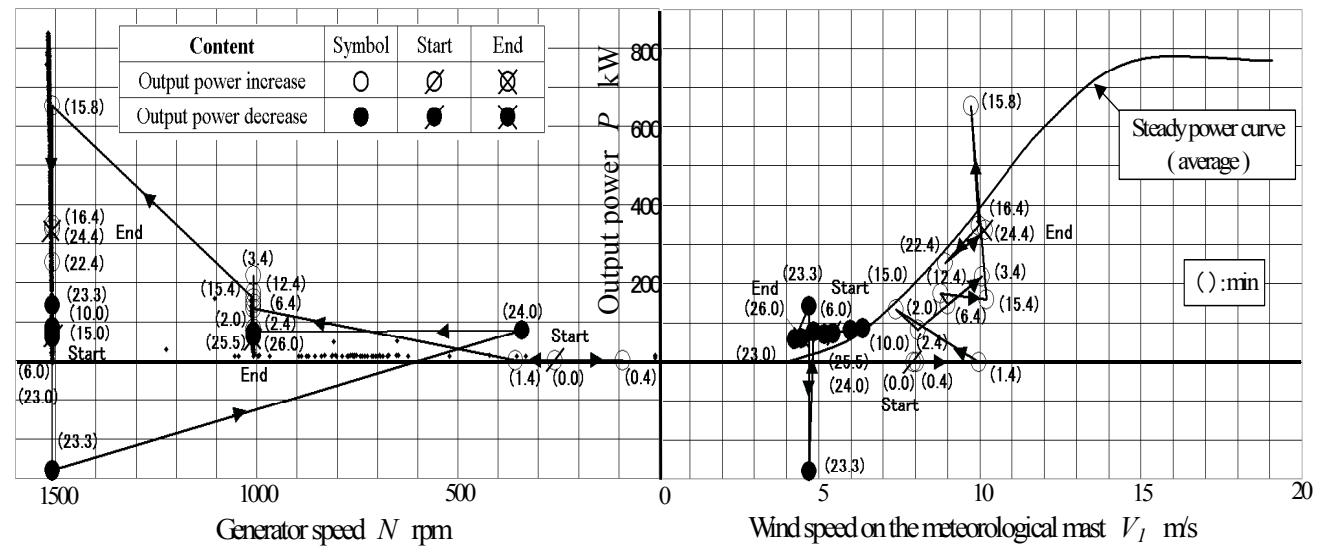

Fig. 9 Loci of operating points in output power transition (Wind turbine B)

The values in parenthesis next to the white circles in Fig. 9 indicate the loci of the active power and generator speed change, in minutes, from the point when the generator speed suddenly began increasing. The values in parenthesis next to the black circles indicate the loci of physical value change from the point when a steady generator speed $(N$ $=1500 \mathrm{rpm}$ ) was maintained, as shown in the time scale of Fig. 8 .

In contrast to the case of wind turbine $\mathrm{A}$ in Fig. 5, the loci of the active power and generator speed versus the wind speed do not follow a steady power curve. This deviation from the steady power curve can be attributed to the slightly inferior controllability of physical values compared to wind turbine A, since the rotor speed is controlled at only two stages (the P4 and P6 states) and the generator speed, in relation to the change in the wind speed, changes drastically.

Wind turbine $\mathrm{B}$ showed a larger deviation from the steady power curve and the behavior did not indicate a quasi-steady change, as compared to wind turbine A. 


\section{Conclusions}

This report discusses the behavior of the transient change when the output power of a wind turbine suddenly changes, for instance when it starts up and stops. It is based on the results of the discussion in the previous report ${ }^{(4)}$ concerning the different characteristics of two wind turbine generator systems with different control methods as established by measuring the wind conditions and various electrical parameters of wind turbine generator systems at the site.

The following points were found in this study.

(1) Comparing wind turbine A (variable-pitch type, equipped with an asynchronous wound-rotor induction generator) and wind turbine B (stall type, equipped with an asynchronous squirrel-cage induction generator), the instantaneous change in various electrical parameters when starting a wind turbine were smaller in the case of wind turbine A. For example, the change in voltage, which influences the grid, was smaller in the case of wind turbine A.

(2) During the transient change with the changes in output power, both wind turbine A and B indicated a close similarity in the waveforms that showed the temporal changes in the active power and current. It became clear that these waveforms also have a direct connection with the change in wind speed over time.

(3) In the case of wind turbine A, it is possible to evaluate the transient change and the output power change in the wind turbine, including the startup and stop of the wind turbine, as a quasi-steady change. However, in the case of wind turbine B, the deviation from the steady power curve is large and the behavior did not follow the quasi-steady change.

\section{References}

(1) Imamura H. et al., Study on the Wind Measurements and Performance Evaluation of a WTGS in Complex Terrain (1st Report, Evaluation of NEDO-500kW WTGS at Tappi Wind Park), Trans. Jpn. Soc. Mech. Eng., Vol. 64, No. 626, B (1998), pp.3323-3329.

(2) Müller S. et al., Doubly Fed Induction Generator Systems for Wind Turbine, IEEE Industry Applications Magazine, May/June 2002, pp.26-33.

(3) Hofmann W., Okafor F., Doubly-Fed Full-Controlled Induction Wind Generator for Optimal Power Utilisation, PEDS '01 Conference Proceedings, (2001), pp.1-7.

(4) Saito S. et al., Performance Comparison of Two Wind Turbine Generator Systems Having Two Types of Control Methods, Trans. Jpn. Soc. Mech. Eng., Vol.70, No.700, B (2004), pp.3174-3181. 